\title{
Impacts of stress, satisfaction and behavioral intention on continued usage: evidence from physicians transitioning to a new drug management system
}

\author{
Rola El Halabieh \\ McGill University \\ Rola.elhalabieh@mcgill.ca
}

\author{
Anne Beaudry \\ Concordia University \\ Anne.beaudry@concordia.ca
}

\author{
Robyn Tamblyn \\ McGill University \\ Robyn.tamblyn@mcgill.ca
}

\begin{abstract}
A survey of physicians taking part in a pilot study involving the transition from an e-prescribing system to a new integrated drug management system was conducted. Data about physicians' level of stress induced by the system transition, satisfaction with the new system, and intention to continue to use the system, were collected as well as system usage logs before, during, and after the transition. Results indicate that physicians experiencing higher level of stress used the new system less during the transition as well as during the two months post-transition than their counterparts who reported lower level of stress. Although satisfaction with the new system was positively related to physicians' intention to use, it was not significantly related to actual usage. A discussion of our results and their implications for research and practice concludes the paper.
\end{abstract}

\section{Introduction}

Research results since the 80 s have contributed to enhance our understanding of the antecedents and dynamics of user acceptance and use of Information Technology (IT). Currently, more often than not, new IT implementations are replacement of older systems. User transition to these new IT is an important phenomenon although overlooked in IS research. Indeed, while much research has investigated factors associated with the adoption of information technology (IT) by healthcare professionals and physicians' reactions to new IT adoption (see [1] for a review), little is known about users' reactions when transitioning to a new system.

Information Technology changes require users to adjust themselves or modify their working processes and usage pattern of the technology. Many upgrades do not involve unlearning a work process fully but require learning where the system functions are relocated or how the functions have changed. Radical changes however require significant changes in the elements of an IT platform and associated work process. Such transitions bring major disruptions to employee work routines. This implies significant changes in users, their work processes and in their IT use routine [2]. This is both shocking and stressful for individuals as they try to cope with the new system requirements [3]. Depending on various factors, such as the magnitude of changes in business processes and technology platforms, the duration of this phase might range from a month to a year or more [3].

While earlier studies examined users' acceptance and use of IT implemented as replacement of paperbased systems, nowadays most studies examine users' reactions to a new IT implemented as a replacement to an older one. Most of these studies however do not take into account usage of the previous system while examining users' reactions to the new IT being implemented whereas studies on usage continuance typically study antecedents of continuous use of an existing system. As a result, we do not know if acceptance and use of the previous IT - the IT that is being replaced by the new one - influences acceptance and use of the new IT during and after the transition. As such, this study seeks to shed light on this phenomena by investigating whether usage level of the previous IT along with satisfaction with the new system and stress experienced during the transition period are related to usage of the new IT. This longitudinal study thus investigated the relationship between physicians' stress and satisfaction experienced during the transition to a new eprescribing system and their actual system usage during a four-month period including two months post-implementation.

\section{Literature Review}

While a number of studies have focused on various antecedents of IT use (e.g., [4]; [5]), the bulk of studies focusing on user acceptance of IT conducted over the last decades stops at users' behavioral intention to use. Others have examined the drivers of intention to continue to use (e.g. [6]). Recently, more studies have examined the triggers of continued use (e.g., [7]; [4]), extended use [8] or effective use [9]. While prior research has significantly contributed to further our understanding of user acceptance and use of IT despite a few exceptions (e.g., [10]) - it largely focuses on users' reactions to a new IT without taking into account usage of the prior system - the one that has 
been replaced by the new studied IT - and rather focuses on other triggers expected to lead individuals to use the new technology.

Transitions, "the process of change between one previously established context and another, and adaptation to new contextual norms and outcomes that ensue" [11] are frequent over the course of human beings' life. Individuals go over transitions in their personal life, family, career, and social life among others. Mikal et al's [11] results indicate that transitions of all kinds are commonly accompanied by negative emotions and increased stress. Furthermore, their results show that individuals experience stress even when transitions are positive, anticipated, and voluntary.

Although it could be expected that transitioning from an older computer-based system to a new one may be easier than the conversion from a paper-based system to a computer-based system, extant literature suggests otherwise. For instance, Abramson [12] conducted interviews with 19 physicians who transitioned from an older electronic health record system (EHR) to a new one. Their results indicate that while ambulatory care practitioners' overall satisfaction increased following the implementation of the new EHR, their ability to perform clinical tasks decreased significantly. Zandieh [13] carried out two cross-sectional surveys of ambulatory care practitioners transitioning to a new EHR. The presurvey took place approximately one year prior to the transition and the post-survey was distributed approximately three months after the implementation of the new system. Their results indicate that practitioners' overall satisfaction increased with the new EHR while their ability to perform clinical tasks decreased significantly. In addition, Pfoh et al's [14] 197 post-transition survey respondents reported software adaptation-related stress as a moderate to major problem.

\subsection{The role of stress}

The introduction of a new IT in the work environment brings procedural changes and individuals need to adapt quickly. Research findings point to various users' reactions from anxiety and anger to happiness and excitement [15]. Stress, anxiety, and tensions experienced by IT professionals due to the ever-changing technical skills that are required to keep pace with technology change has been related to decreased productivity and increased turnover [16]; [17].

The term being under stress has been defined as a "psychological reaction to some sort of an imbalance between a person and the environment" [18]. Stress is experienced when there is a substantial difference between the demands from the environment and the person's capability to respond to them or when a significant negative consequence is anticipated from not meeting those demands [19]. Daily stress has been found positively related to negative affect and negatively related to state mindfulness, non-hedonic well-being, environmental mastery, meaning in life, social connectedness, perceived productivity, and sleep quality [20]. Work related stress results in dissatisfaction at work, lack of job involvement, and poor job performance [21]. More specifically, technostress has been found to be negatively related to individual productivity [22] and performance [23].

IT related stress has been found to be triggered by technology characteristics [24] and changing work environment [26]. IT implementations are generally expected to lead to gains for the organization and its employees. However, new IT adds information overload and accelerates the pace of work through demands for greater response immediacy. Moreover, the need to become familiar with the new IT poses a threat to individuals' security, confidence, and qualifications. Stress reduces one's ability to perform by diverting effort from job performance to coping with the stressors [25] and has been found to be negatively related to performance and productivity [26].

\subsection{The role of satisfaction}

Satisfaction with an IT, (i.e., a positive affective state resulting from a cognitive appraisal of the IT) has been found to be positively related to intention to continue to use, (e.g., [6]; [7]). Thong [17] suggest the existence of a lower bound of satisfaction below which users may discontinue their usage of an IT. It has been suggested that a system's use must fulfill user's needs in which case user satisfaction with the system will increase and lead to greater use [27]. Conversely, if usage of the system does not meet user needs, satisfaction will decrease and, in turn, its usage will decrease too.

\section{Research Model and Hypotheses}

Figure 1 offers a graphical representation of our research model and depicts the objectives of this study which were to assess the level of stress and satisfaction experienced by physicians during the transition to the new e-prescribing system and examine how stress and satisfaction related to intention to continue to use and actual usage of the new system during the transition and over a period of two months post-transition.

Beaudry \& Pinsonneault's [15] study suggests that a number of individuals experience anxiety at the 
announcement of the forthcoming replacement of the system they currently use. Strong emotions such as anxiety and frustration have been found to be directly negatively related to intention to use [4] and to IT use $[15 ; 28 ; 29]$. Such emotions may be more important determinants of continued use than behavioral intention [30]. We thus hypothesize that greater stress triggered by the implementation of the new IT will be negatively related to physicians intention to continue to use the system.

\section{$\mathrm{H1}$ : Stress is negatively related to intention to} continue to use.

Strong emotions such as anxiety and frustration have been found to be directly negatively related to IT use [e.g., [11]; [15]]. As such,

$\mathrm{H} 2$ : Stress is negatively related to continued use.

Building on expectation confirmation theory, much research has been devoted to studying the relationship between satisfaction and intention to continue to use an IT. Satisfaction has repeatedly been found to be positively related to intention to continue to use (e.g. [6] [31] [7] [32]). Hence:

\section{H3: Satisfaction is positively related to intention to continue to use.}

Little is however known about the role of satisfaction on actual usage continuance. Thorngate [33] argued that "If a response generated in an interaction is judged to be satisfactory, it will tend to be reproduced under subsequent, equivalent circumstances from habit rather than thought" (p. 32). Drawing on [33] and previous study results (e.g. [34]), satisfaction with an IT should be directly and positively related to continued use hence the following hypothesis:

H4: Satisfaction is positively related to continued use.

Behavioral intention, "the degree to which an individual has formulated conscious plans to perform or not some specified future behavior" has been long established [5] and has been widely used and found as a predictor of IT use (see [4] for a review). As such, in light of extent research, we hypothesize:

H5: Intention to continue to use is positively related to continued use.

Ajzen [35] argues that past behavior is an effective indicator of future behavior. It has further been argued that much of continued IT use was habitual and that in such a case, intention loses its predictive power [7]. Ortiz de Guinea and Markus [30] argue that habits and environmental cues such as the task one intends to perform are more important triggers of continued use than behavioral intention. In this perspective, prior usage may be a better predictor of use than intention in the case of a transition from an older to a new system. Hence our last hypothesis:

H6: Prior usage is positively related to continued use.

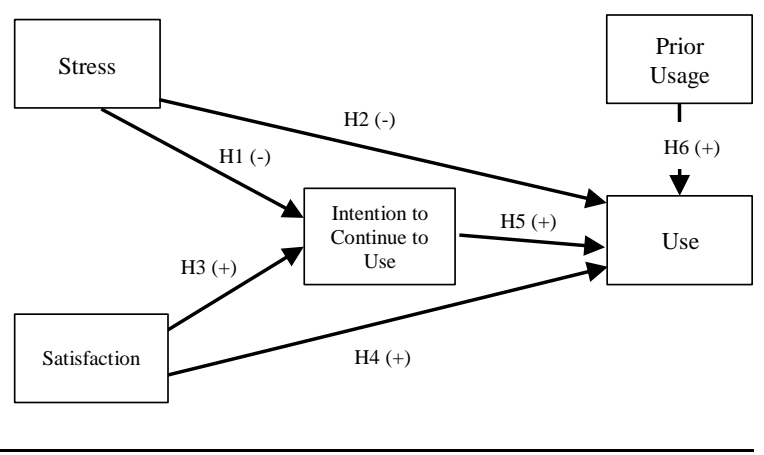

Figure 1. Research model

\section{Research method}

\subsection{Study setting}

The present study examines the reactions of primary care physicians in response to a significantly new version of the e-prescribing system they were using. Research indicates that e-prescribing systems contribute to reducing error rates and improve medication safety (e.g., [12]; [36]; [37]). Despite such benefits, various factors such as costs and perceived negative impact on the time and workflow of the practicing physician [38] have contributed to hinder their adoption. Initiatives such as Centers for Medicare \& Medicaid Services (CMS) in the USA promote adoption of integrated e-prescribing systems within electronic health records systems. As a result, many prescribers are likely to switch from home grown stand-alone systems to newer ones in the near future [12].

The physicians were initially using MOXXI (Medical Offices for the XXIst Century) an eprescribing system running on a handheld device [39]. The new system, MOXXI NEW GENERATION (NG), instituted several important changes. First, the technology moved from local database using Oracle mobile with periodic synchronization to a web-based e-prescribing and integrated drug management system. Second, physicians were given tablet PCs to replace their mobile devices. Third, the user interface changed to adopt web-based standards and enable more information to be simultaneously displayed to improve the efficiency of drug management decision-making. 
These changes allowed physicians to write prescriptions from any location, retrieve the drug history, recent emergency room visits and hospitalizations and have a patient's drug, disease, and allergy profile reviewed for potential prescribing problems. This valuable patient medical information is available to physicians by daily updates to the central server for all of the physician's patients from the RAMQ (the Quebec universal health insurance agency). The RAMQ maintains a database of all Quebec beneficiaries (name, age, gender, residence), all medical services received by beneficiaries (date, diagnosis, type and location of service and provider), and medications received (medication, date dispensed, prescribing physician and dispensing pharmacist, quantity and duration of prescription).

\subsection{Study population}

The 75 primary care physicians (41 males and 34 females) who transited from the older MOXXI system to MOXXI NG were the population under study. On average, these physicians have been practicing for 30 years, ranging from 10 to 49 years. Following information sessions, physicians received a two-hour training session on the new system. The format of the training was either one-on-one or in small groups. The trainer demonstrated how to perform each task and then asked each physician to perform a similar one by him/herself. Even within the group training, one-on one support was provided to ensure the acquisition of the right skills for using the new system. Telephone, online, and on-site support was available at all times during the transition period. A follow-up visit was made to the physician's practice within three weeks of the transition. The purpose of this visit was to answer any questions that the physician had, to assess the physician's use of the system, and to administer the questionnaire used in this study.

\subsection{Measures}

Stress experienced by physicians transitioning to the new system was measured using [40] one-item measure adapted to our context: "Indicate to what extent using the new MOXXI NG system makes you feel stressed" with the following scale: no stress at all, very little stress, little stress, some stress, much stress, very much stress and caused me to panic. This item asked directly about the level of stress and attempted to evaluate the "overall" stress experienced by the users. In addition, we used a 3-item measure of stress which asked respondents if they felt 1) tense, 2) restless, and 3) anxious while using the new system [41]. Physicians were asked to respond on a 7-level Likert scale ranging from totally disagree to totally agree for each item.
Satisfaction with the new system was assessed using a measurement instrument from [6]. Physicians were asked to indicate their level of satisfaction with the new MOXXI NG on a 7-point semantic differential scale for four opposite pairs: dissatisfied / satisfied, displeased / pleased, frustrated / contented, and terrible / delighted.

Intention to continue to use MOXXI NG was measured using three items adapted from [42]. Physicians were asked to indicate the extent at which they agreed with each item on a Likert-7 level scale ranging from totally disagree to totally agree. The items used to measure intention to continue to use were: "I intend to continue using MOXXI NG rather than discontinue its use", "My intentions are to continue using MOXXI NG than use any alternative" and "If I could, I would like to continue my use of MOXXI NG". System usage was measured with a ratio calculated using audit trails of physician's use documented by the system and the number of patients seen based on medical services visit claims data available from RAMQ for the 4-month period of the study: 1 month pre-transition, 1 month per-transition, and 2 months post-transition. The denominator was the number of visits made by MOXXI-consented patients per month. The numerator was the number of visits in which an e-prescription was written for these patients through the system.

\section{Results}

Data analysis proceeded as follows. We first estimated the linear correlation between our two stress measures using Pearson correlations. Confirmatory factor analysis was performed to assess the validity of the stress, satisfaction, and intention to use measures. Convergent validity was assessed by examining the item loadings and cross-loadings. Discriminant validity was assessed by comparing the square root of the average variance extracted (AVE) of each construct against the inter-construct correlations. Reliability was assessed with composite reliability (CR) since Cronbach's alpha often severely underestimates the internal consistency reliability of latent variables in PLS path models. The composite reliability takes into consideration that indicators have different loadings, and may be interpreted similarly to Cronbach's alpha [43]. To estimate the association between the stress and satisfaction experienced during system transition, behavioral intention, and actual system's utilization, a structural equation model was used. Physician was the unit of analysis, stress and satisfaction were the independent variables and utilization rate was the outcome variable. Behavioral intention to use was modeled as a mediating variable. The data was analyzed using SmartPLS 2.0 [44]. To 
test the significance of path coefficient estimates, bootstrapping, a resampling technique, was used. Bootstrapping treats the sample as if it represents the population and creates a large number of samples by randomly drawing cases with replacement from the original sample. SmartPLS estimates the path model for each bootstrap sample. The obtained path model coefficients can be viewed as an approximation of the sampling distribution [43]. We have run the bootstrap algorithm with parameters set to 75 cases and 500 resamples as recommended [45]. Lastly, to better understand the role of stress and satisfaction, we tested the difference in usage rates among physicians who were above or below the mean in the distributions of stress and satisfaction using T-Tests.

\subsection{Measurement instruments' reliability and validity}

As expected, the two stress measures were strongly correlated $(\mathrm{r}=0.82, \mathrm{p}<.001)$. We thus decided to drop the Bentley and Jones' [40] one-item measure from further analysis and keep only the 3-item instrument from [41]. The confirmatory factor analysis returned three clean factors for satisfaction, stress, and intention to continue to use with Eigen values of 3.146, 2,427, and 2,412 respectively. The cumulative variance explained by the three factors was $79.98 \%$. There was strong convergent validity as all items largely loaded on their respective construct and the average variance extracted were all greater than 0.5. As shown in Table 1 , all measures showed very good reliability with $\mathrm{CR}$ scores well exceeding the recommended threshold of 0.7 . The square root of the average variance extracted (AVE) (bold diagonal elements) were all found to be greater than any inter-construct correlation (offdiagonal elements) hence indicating good discriminant validity.

\subsection{Structural model}

Contrary to our expectations (H1), stress was not significantly related to intention to continue to use but, as expected, was negatively directly related to actual use during the transition month $(-0.368, \mathrm{p}<.001)$ and for the two months post-transition hence supporting $\mathrm{H} 2$ (see Table 2). Inversely, satisfaction was positively related to intention to continue to use $(0.578, \mathrm{p}<.001)$ at transition time thus supporting $\mathrm{H} 3$. However, contrary to our expectations, satisfaction was not significantly related to actual use (H4) for any of the three months under study.

Intention to continue to use was not significantly related to use during the transition month or the following one but was significantly related to use two months post-transition thus providing mitigated support for H5. Lastly, prior use was strongly positively related to continued usage for the three months under study hence supporting H6. The model contributed to explain $52.8 \%$ of the variance of usage during the transition month, $55.9 \%$ one month posttransition, and $65.7 \%$ two months post-transition.

\subsection{Post-Hoc Analyses}

We performed T-tests to compare respondents who experienced lower and higher levels of stress and satisfaction to further our understanding of their role on actual usage.

Table 1. Measurement instruments' reliability and validity

\begin{tabular}{|c|c|c|c|c|c|c|c|c|c|}
\hline \multirow{2}{*}{ Construct } & \multirow{2}{*}{ Indicator } & \multirow{2}{*}{$\begin{array}{c}\text { Item } \\
\text { Loading }\end{array}$} & \multirow{2}{*}{$\begin{array}{l}\text { Average } \\
\text { Variance } \\
\text { Extracted }\end{array}$} & \multirow{2}{*}{$\begin{array}{l}\text { Composite } \\
\text { Reliability }\end{array}$} & \multirow{2}{*}{$\begin{array}{c}\text { Construct } \\
\text { Mean }\end{array}$} & \multirow{2}{*}{$\begin{array}{l}\text { Standard } \\
\text { Deviation }\end{array}$} & \multicolumn{3}{|c|}{ Constructs' Correlations } \\
\hline & & & & & & & Intention & Satisfaction & Stress \\
\hline \multirow{3}{*}{$\begin{array}{c}\text { Intention to } \\
\text { Continue to } \\
\text { Use }\end{array}$} & rather than not & 0.900 & & & & & & & \\
\hline & rather than alternative & 0.871 & & & & 2.599 & 0.880 & & \\
\hline & would like to & 0.870 & 0.775 & 0.912 & 18.200 & & & & \\
\hline \multirow{4}{*}{ Satisfaction } & contented & 0.894 & & & & & & & \\
\hline & pleased satisfied & 0.907 & & & & & & & \\
\hline & & 0.933 & 0.784 & 0.935 & 21.086 & 4.727 & $0.605 * *$ & 0.885 & \\
\hline & delighted & 0.801 & & & & & & & \\
\hline \multirow{3}{*}{ Stress } & tense & 0.846 & & & & & & & \\
\hline & restless & 0.911 & 0.771 & 0.91 & 8.666 & 4.169 & $-0.368 *$ & $-0.553 * *$ & 0.878 \\
\hline & anxious & 0.875 & & & & & & & \\
\hline
\end{tabular}


Table 2. Results

\begin{tabular}{|c|c|c|c|c|c|c|}
\hline Hypotheses & Direction & Result & Construct pairs & B & $\mathrm{T}$ & $p$ \\
\hline \multicolumn{7}{|c|}{ Transition month } \\
\hline H1 & Negative & Not supported & Stress $\rightarrow$ Intention & -0.054 & 0.552 & .582 \\
\hline $\mathrm{H} 2$ & Negative & Supported & Stress $\rightarrow$ Use & -0.368 & 3.297 & .001 \\
\hline H3 & Positive & Supported & Satisfaction $\rightarrow$ Intention & 0.578 & 3.357 & .001 \\
\hline $\mathrm{H} 4$ & Positive & Not supported & Satisfaction $\rightarrow$ Use & 0.181 & 1.465 & .147 \\
\hline H5 & Positive & Not supported & Intention $\rightarrow$ Use & 0.026 & 0.260 & .795 \\
\hline H6 & Positive & Supported & Use prior month $\rightarrow$ Use & 0.647 & 3.392 & .001 \\
\hline \multicolumn{7}{|c|}{ One month post-transition } \\
\hline $\mathrm{H} 2$ & Negative & Supported & Stress $\rightarrow$ Use & -0.367 & 3.297 & .001 \\
\hline $\mathrm{H} 4$ & Negative & Not supported & Satisfaction $\rightarrow$ Use & -0.151 & 1.026 & .308 \\
\hline H5 & Positive & Not supported & Intention $\rightarrow$ Use & 0.167 & 1.412 & .162 \\
\hline H6 & Positive & Supported & Use prior month $\rightarrow$ Use & 0.748 & 3.423 & .001 \\
\hline \multicolumn{7}{|c|}{ Two months post-transition } \\
\hline $\mathrm{H} 2$ & Negative & Supported & Stress $\rightarrow$ Use & -0.402 & 3.299 & .001 \\
\hline $\mathrm{H} 4$ & Positive & Not supported & Satisfaction $\rightarrow$ Use & -0.208 & 1.555 & .124 \\
\hline H5 & Positive & Supported & Intention $\rightarrow$ Use & 0.251 & 3.220 & .001 \\
\hline H6 & Positive & Supported & Use prior month $\rightarrow$ Use & 0.811 & 3.426 & .001 \\
\hline
\end{tabular}

5.3.1. The role of stress. To compare the results for physicians experiencing lower stress to those having acknowledged being more stressed, the sample mean on stress (8.66) was used as the cut-off point to create two groups. The "low stress" group comprises 35 respondents with a mean stress score of 4.89 (SD: 1.75). The "high stress" group comprises 40 respondents with a mean stress score of 11.98 (SD: 2.51).

As can be seen from Table 3, stress level was not associated with intention to continue to use the new system. Stress was however significantly related to satisfaction and actual use such that physicians experiencing lower stress were more satisfied with the new system and used it more during the transition and the two following months. Interestingly, physicians who used the old system less during the month prior to the transition reported higher stress than their counterparts who used it more. We found no significant difference in stress level between males and females nor among younger and older physicians (data not shown).

5.3.2. The role of satisfaction. We followed the same procedure to compare physicians who were more and less satisfied with the new system. The sample mean for satisfaction level in the study population was 21.08 , whereby the "low satisfaction" group comprising 33 respondents had a mean satisfaction level of 16.74 (SD: 3.28) and the "high satisfaction" group comprising 42 physicians had a mean satisfaction rating of 24.5 (SD: 2.19).

As shown in Table 4, satisfaction level was significantly associated with stress and intention to continue to use. Physicians who were more satisfied with the new system experienced less stress and had higher intention to use it than their counterparts who were less satisfied. Satisfaction level however did not make a significant difference on actual usage of the system during the transition. More satisfied physicians used the new system slightly one month post-transition but there was no significant usage level difference afterward. We found no significant difference on satisfaction level between genders nor for younger vs older physicians (data not shown).

\section{Discussion}

As more physicians will increasingly move to new e-health systems over the coming years, research is needed to understand and properly manage such transitions. Our study sheds new light on the impact of stress and satisfaction felt by physicians during the transition to a new e-prescribing system on their continued use. On the one hand, our results indicate that physicians who experienced higher levels of stress at the transition ended-up using the new system less than their counterparts who were less stressed. 
Table 3. T-tests results for low and high stress

\begin{tabular}{|c|c|c|c|c|c|}
\hline Variable & Stress & Mean & $\mathrm{T}$ & $p$ value & Cohen's $d$ \\
\hline \multirow{2}{*}{ Satisfaction } & Low & 22.974 & \multirow{2}{*}{3.542} & \multirow{2}{*}{.001} & \multirow{2}{*}{0.811} \\
\hline & High & 19.437 & & & \\
\hline \multirow{2}{*}{ Intention } & Low & 18.628 & \multirow{2}{*}{1.383} & \multirow{2}{*}{.170} & \multirow{2}{*}{0.315} \\
\hline & High & 17.825 & & & \\
\hline \multirow{2}{*}{ Use at transition } & Low & $\begin{array}{l}.019 \\
.436\end{array}$ & \multirow{2}{*}{2.783} & \multirow{2}{*}{.007} & \multirow{2}{*}{0.647} \\
\hline & High & & & & \\
\hline \multirow{2}{*}{ Use 1 month post-transition } & Low & .610 & \multirow{2}{*}{2.702} & \multirow{2}{*}{.009} & \multirow{2}{*}{0.626} \\
\hline & High & .442 & & & \\
\hline \multirow{2}{*}{ Use 2 months post-transition } & Low & .594 & \multirow{2}{*}{3.626} & \multirow{2}{*}{.001} & \multirow{2}{*}{0.844} \\
\hline & High & .371 & & & \\
\hline
\end{tabular}

Table 4. T-test results for low and high satisfaction

\begin{tabular}{|c|c|c|c|c|c|}
\hline Variable & Satisfaction & Mean & $\mathrm{T}$ & $p$ value & Cohen's $d$ \\
\hline \multirow{2}{*}{ Stress } & Low & 10.668 & \multirow{2}{*}{3.981} & \multirow{2}{*}{.000} & \multirow{2}{*}{0.933} \\
\hline & High & 7.095 & & & \\
\hline \multirow{2}{*}{ Intention } & Low & 16.666 & \multirow{2}{*}{4.889} & \multirow{2}{*}{.000} & \multirow{2}{*}{1.180} \\
\hline & High & 19.404 & & & \\
\hline \multirow{2}{*}{ Use at transition } & Low & .493 & \multirow{2}{*}{0.737} & \multirow{2}{*}{.463 } & \multirow{2}{*}{0.169} \\
\hline & High & .543 & & & \\
\hline \multirow{2}{*}{ Use 1 month post-transition } & Low & .454 & \multirow{2}{*}{1.882} & \multirow{2}{*}{.064} & \multirow{2}{*}{0.433} \\
\hline & High & .572 & & & \\
\hline \multirow{2}{*}{ Use 2 months post-transition } & Low & .419 & \multirow{2}{*}{1.526} & \multirow{2}{*}{.131} & \multirow{2}{*}{0.355} \\
\hline & High & .519 & & & \\
\hline
\end{tabular}

This result is in line with - and reinforces results from - prior studies having found a negative relationship between anxiety and use (e.g., [15] [29]). On the other hand, satisfaction felt at the transition even though positively related to intention to use was not significantly related with actual use during the three months of our study. Satisfaction only made an inconsequential difference in terms of usage for highly satisfied physicians one month post-transition.

The strong relationship between prior usage (one month pre-transition) and usage for the three following months (per- and post-transition) in conjunction with the non-significant relationships between intention to use and actual use rates suggests that physicians may have a consistent behavior over time. Two months post-transition - whether they were initially low or high users - physicians' usage remained constant. This result is in line with the habitual use hypothesis as suggested by [30]. In our study, lower users prior to the transition were also those who experienced more stress during the transition.
It is possible that the stress experienced at the transition was, at least in part, due to IT-related anxiety or low computer self-efficacy leading to their habitual low level of use of the prior system. One could argue that physicians who were higher users of the prior system felt less stress as they could transfer their knowledge of the old system to the new one.

A seemingly surprising result lies in the nonsignificant relationship between intention to use and continued use during the transition as well as one month post-transition. This is however in line with prior studies (e.g., [46] [5] [47]). As outlined by [47], prior studies suggest that results obtained from objective usage measures, such as this study, significantly differ from results derived from studies relying on subjective measures where respondents may have a tendency to over-estimate their actual use of the system. Limayem [7] further argued that, at least in the case of IS continuance, circumstances might exist under which the effect of intention on use could be partly or even entirely suppressed. Recently, many scholars have urged researchers studying IT acceptance not to stop at behavioral intention but to 
include measurements for actual use (e.g., [7] [47]). Our study takes a step in that direction. In fact, very few studies have examined the relationship between intention and continued use and we could not find any study having examined this relationship relying on objective measures of usage such as in our study.

\subsection{Limitations}

The results reported here should be interpreted in light of the study's limitations. First, the sample size of 75 was rather small. Nevertheless, the variance in the data was sufficient to provide satisfying statistical power and to detect significant effects. Clearly, larger samples are required to further validate our findings and more research is needed to assess their generalizability. Still, our usage measure, being objective rather than subjective, allows for confidence in the results.

Second, we did not assess whether physicians were using the system's functionalities correctly. Hence, we do not know if they made more or less errors while using the new system or took more time to write their prescriptions. Future studies should take such issues into account as effective use [9] is of utmost importance in creating the expected value from IT investments in health care.

The design of the study might have affected the results. The questionnaire provides a cross-sectional snapshot of all the constructs under study except usage which was a continuous collection of data over a 4month period. In fact, physician's satisfaction and stress level may have changed during the transition period. Hence, the collected data may not be representative of the overall satisfaction and stress level experienced by the physicians over the period of the study. Despite its limitations, this study offers a number of contributions for research and practice.

\subsection{Contributions for research.}

From a theoretical standpoint, while the current study examined use continuance behavior of physicians, its findings have important implications for other types of users and systems as well. For instance, it highlights the importance to take into account the usage patterns of the prior system to better understand continued usage post transition. Our results also indicate that stress is experienced by physicians not only for new IT but also during transitions.

Few studies have examined the relationship between intention and actual system use. To our knowledge, this is the first study to examine the role of stress, satisfaction and intention at implementation time with actual usage data up to 2 months postimplementation and to compare usage rates during and post-implementation with those from the month prior to transition. Our results suggest that previous usage may be a good predictor of future use and thus should be taken into account in future studies. Our results further suggest that the effect of stress experienced during the transition to the new system had a stronger and longer lasting effect on usage than that of satisfaction. This result appears an interesting contribution to research as users' stress level has been practically overlooked in IT acceptance studies.

\subsection{Contributions for practice.}

Our results emphasize the importance to acknowledge that users experience varied levels of stress during a system transition which may impact their level of use of the new system. Stress has long been known to be significantly related to psychological symptoms and somatic health. As such, early interventions and implementation of prevention mechanisms and strategies are of utmost importance. This suggests that implementers should pay attention to the stress experienced by user transitioning to a new system. The identification of the best means to reach this goal is beyond the scope of the current study but certainly longer individualized training and support figure among the candidates toward achieving it.

Knowing that individuals previous level of use is an indicator of future use of the new systems, in settings where use cannot be enforced, our results suggest that implementers should assess usage levels prior to transitioning to the new system and identify reasons underlying lower usage levels. This knowledge could help them focus their attention on, and provide better support to, individuals who need it the most. For all stakeholders to reap the benefits of inter-organizational systems such as healthcare systems, widespread use is required. Our results suggest that lower users of systems in place may repeat their use pattern and experience more stress during a transition to a new system than their counterparts who are heavy users.

\subsection{Future Research}

Future research should further examine the role of users' satisfaction with the IT being replaced on satisfaction and usage of the new one. Individuals who are unsatisfied with a given IT may be more satisfied with the new IT and use it more than their counterparts who were satisfied with the IT being phased out. As well, satisfaction and stress should be assessed prior, during, and after the transition to further our understanding of their role on continued usage and to allow for assessment of any training efforts. 
In addition, future research efforts should be undertaken to delve into what exactly is stressful in a new system transition. Our measure of stress asked physicians to indicate the extent at which the new system made them feel stressed. It would appear important to further our understanding with regard to the exact triggers of stress among users. Indeed, we do not know if the new device, some specific features, the risk of making errors, or the longer time required to complete the task, among others, triggered stress among our respondents. Such finer-grained understanding is most important for systems' designers, implementers, and trainers aiming at providing better systems and support to users.

\section{Conclusion}

Our results draw attention to the stress experienced by physicians transitioning to a new system which was found to be negatively related to continued use up to two months post-transition. Despite the fact that transitioning to a new system may seem easier than moving from a paper-based to a computer-based system, our results indicate that users feel some stress during a transition. Our results also suggest that satisfaction and intention to use a new system may not necessarily be the best predictors of continued use in a system transition situation. Implementers should also pay attention to lower users pre-transition as our results suggest that even though they declare being satisfied with the new system, they may not use it more than the previous one. These individuals, whether they experience low or high stress, may also need more help and support during the transition.

\section{References}

[1] M.-P. Gagnon, et al., "Systematic Review of Factors Influencing the Adoption of Information and Communication Technologies by Healthcare Professionals," Journal of Medical Systems, vol. 36, 2012, pp. 241-277.

[2] A. Beaudry and A. Pinsonneault, "Understanding User Responses to Information Technology: A Coping Model of User Adaptation," MIS Quarterly, vol. 29, no. 3, 2005, pp. 493-524.

[3] H. Bala and V. Venkatesh, "Changes in Employees' Job Characteristics during an Enterprise System Implementation: A Latent Growth Modeling Perspective," MIS Quarterly, vol. 37, no. 4, 2013, pp. 1113-1140.

[4] V. Venkatesh, et al., "User Acceptance of Information Technology: Toward a Unified View," MIS Quarterly, vol. 27, no. 3, 2003, pp. 425-478.

[5] S. Taylor and P.A. Todd, "Understanding Information Technology Usage - a Test of Competing Models,"
Information Systems Research, vol. 6, no. 2, 1995, pp. 144176

[6] A. Bhattacherjee, "Understanding information systems continuance: An expectation-confirmation model," MIS Quarterly, vol. 25, no. 3, 2001, pp. 351-370.

[7] M. Limayem, et al., "How Habit Limits the Predictive Power of Intention: The Case of Information Systems Continuance," MIS Quarterly, vol. 31, no. 4, 2007, pp. 705737.

[8] J.J.P.-A. Hsieh and W. Wang, "Explaining employees' Extended Use of complex information systems," European Journal of Information Systems, vol. 16, no. 3, 2007, pp. 216227.

[9] A. Burton-Jones and C. Grange, "From Use to Effective Use: A Representation Theory Perspective," Information Systems Research, vol. 24, no. 3, 2012, pp. 632 - 658.

[10] M. Keil, et al., "Usefulness and Ease of Use - Field Study Evidence Regarding Task Considerations," Decision Support Systems, vol. 13, no. 1, 1995, pp. 75-91.

[11] J.P. Mikal, et al., "Transition, stress and computermediated social support," Computers in Human Behavior, vol. 29, 2013, pp. A40-A53.

[12] E.L. Abramson, et al., "Physician Experiences Transitioning between an Older versus Newer Electronic Health Record for Electronic Prescribing," International Journal of Medical Informatics, vol. 81, 2012, pp. 539-548.

[13] S.O. Zandieh, et al., "Transitioning Between Ambulatory EHRs: A Study of Practitioners' Perspectives," Journal of the American Medical Informatics Association, vol. 19, 2012, pp. 401-406.

[14] E.R. Pfoh, et al., "Satisfaction After the Transition Between Electronic Health Record Systems at Six Ambulatory Practices," Journal of Evaluation in Clinical Practice, vol. 18, 2012, pp. 1133-1139.

[15] A. Beaudry and A. Pinsonneault, "The Other Side of Acceptance: Studying the Direct and Indirect Effects of Emotions on Information Technology Use," MIS Quarterly, vol. 34, no. 4, 2010, pp. 689-710.

[16] V. Sethi, et al., "What Causes Stress in Information Systems Professionals," Communications of the ACM, vol. 47, no. 3, 2004, pp. 99-102.

[17] J.Y.L. Thong and C.-S. Yap, "Information Systems and Occupational Stress: A Theoretical Framework," Omega, vol. 28, no. 6, 2000, pp. 681-692.

[18] C.L. Cooper, et al., Organizational Stress: A Review and Critique of Theory, Research, and Applications, Sage, 2001.

[19] J.E. McGrath, Social and Psychological Factors in Stress, Holt, Rinehart and Winston, Inc., 1970.

[20] K. Kushlev and E.W. Dunn, "Checking email less frequently reduces stress," Computers in Human Behavior, vol. 43, 2015, pp. 220-228.

[21] S.E. Jackson and R.S. Schuler, "A Meta-Analysis and Conceptual Critique of Research on Role Ambiguity and Role Conflict in Work Settings," Organizational Behavior and Human Decision Processes, vol. 36, no. 1, 1985, pp. 1678. 
[22] M. Tarafdar, et al., "The impact of technostress on role stress and productivity," Journal of Management Information Systems, vol. 24, no. 1, 2007, pp. 301-328.

[23] M. Tarafdar, et al., "Impact of technostress on end-user satisfaction and performance," Journal of Management Information Systems, vol. 27, no. 3, 2011, pp. 303-334.

[24] R. Ayyagari, et al., "Technostress: Technological antecedents and implications," MIS Quarterly, vol. 35, no. 4, 2011, pp. 831-858.

[25] M. Westman and D. Eden, "The Inverted-U Relationship Between Stress and Performance: A Field Study," Work \& Stress, vol. 10, no. 2, 1996, pp. 165-173.

[26] T.S. Ragu-Nathan, et al., "The Consequences of Technostress for End Users in Organizations: Conceptual Development and Empirical Validation," Information Systems Research, vol. 19, no. 4, 2008, pp. 417-433.

[27] J.J. Baroudi, et al., "An Empirical Study of the Impact of User Involvement on System Usage and Information Satisfaction," Communications of the ACM, vol. 29, no. 3, 1986, pp. 232-238.

[28] D.R. Compeau and C.A. Higgins, "Application of Social Cognitive Theory to Training for Computer Skills," Information Systems Research, vol. 6, no. 2, 1995, pp. 118143.

[29] D.R. Compeau and C.A. Higgins, "Computer SelfEfficacy: Development of a Measure and Initial Test," MIS Quarterly, vol. 19, no. 2, 1995, pp. 189-211.

[30] A. Ortiz de Guinea and M.L. Markus, "Why Break the Habit of a Lifetime? Rethinking the Roles of Intention, Habit, and Emotion in Continuing Information Technology Use," MIS Quarterly, vol. 33, no. 3, 2009, pp. 433-444.

[31] L. Deng, et al., "User experience, satisfaction, and continual usage intention of IT," European Journal of Information Systems, vol. 19, no. 1, 2010, pp. 60-75.

[32] C. Liao, et al., "Theory of Planning Behavior (TPB) and Customer Satisfaction in the continued use of e-services: An integrated Model," Computers in Human Behavior, vol. 23, 2007, pp. 2804-2822.

[33] W. Thorngate, "Must We Always Think Before We Act?," Personality and Social Psychology Bulletin, vol. 2, no. 1, 1976, pp. 31-35.

[34] A. Rai, et al., "Assessing the validity of IS success models: An empirical test and theoretical analysis," Information Systems Research, vol. 13, no. 1, 2002, pp. 5069.

[35] I. Ajzen, "The Theory of Planned Behavior," Organizational Behavior and Human Decision Processes, vol. 50, no. 2, 1991, pp. 179-211.

[36] C.M. DesRoches, et al., "Differences Between Integrated and Stand-Alone E-Prescribing Systems Have Implications for Future Use," Health Affairs, vol. 29, no. 12, 2010, pp. 2268-2277.

[37] R. Kaushal, et al., "Electronic Prescribing Improves Medication Safety in Community-Based Office Practices," Journal of General Internal Medicine, vol. 25, no. 6, 2010, pp. 530-536.

[38] L. Poissant, et al., "The Impact of Electronic Health Records on Time Efficiency of Physicians and Nurses: A
Systematic Review," Journal of the American Medical Informatics Association, vol. 12, no. 5, 2005, pp. 505-516.

[39] R. Tamblyn, et al., "The Development and Evaluation of an Integrated Electronic Prescribing and Drug Management System for Primary Care," Journal of the American Medical Informatics Association, vol. 13, no. 2, 2006, pp. 148-159.

[40] P.J. Brantley and G.N. Jones, Daily Stress Inventory, Odessa: Psychological Assessment Resources, Inc., 1989.

[41] D. Watson, et al., "Development and Validation of Brief Measures of Positive and Negative Affect: The PANAS Scales," Journal of Personality and Social Psychology, vol. 54, no. 6, 1988, pp. 1063-1070.

[42] F.D. Davis, et al., "User Acceptance of Computer Technology - a Comparison of Two Theoretical-Models," Management Science, vol. 35, no. 8, 1989, pp. 982-1003.

[43] J. Henseler, Ringle, M., and Sinkovics, R.R., "The use of partial least squares path modeling in international marketing," New Challenges to International Marketing, Advances in International Marketing 20, P. N. G. Rudolf R. Sinkovics, ed., Emerald Group Publishing Limited, 2009, pp. 277-319.

[44] C.M. Ringle, Wende, S. and Will, A., "SmartPLS2.0," 2005; http://www.smartpls.de.

[45] J.F. Hair, et al., "PLS-SEM: Indeed a Silver Bullet," Journal of Marketing Theory and Practice, vol. 19, no. 2, 2011, pp. 139-151.

[46] B. Pynoo, et al., 'Predicting secondary school teachers' acceptance and use of a digital learning environment: a crosssectional study," Computers in Human Behavior, vol. 27, 2011, pp. 568-575.

[47] J. Wu and H. Du, "Toward a better understanding of behavioral intention and system usage constructs," European Journal of Information Systems, vol. 21, no. 6, 2012, pp. 680698.

[48] J.M. Ortega Egea and M.V. Roman Gonzalez, "Explaining physicians' acceptance of EHCR systems: An extension of TAM with trust and risk factors," Computers in Human Behavior, vol. 27, 2011, pp. 319-332. 